\title{
STUDY ON SURFACE MICRO TEXTURED TOOL CUTTING PERFORMANCE BASED ON ADVANTEDGE
}

\author{
Yongbo Zhang ${ }^{1}$, Minliang Zhang ${ }^{2}$ \\ ${ }^{1}$ School of Mechanical Engineering, Shanghai University of Engineering Science, Shanghai, China \\ ${ }^{2}$ School of Mechanical Engineering, Shanghai University of Engineering Science, Shanghai, China
}

\begin{abstract}
In recent years, cutting tools with micro texture are popular with many researches. Front cutting surfaces of tools with a certain micro texture shows different cutting performance with ordinary cutting tools. In order to study Carbide cutting tool's cutting performance with micro channel texture on the rake face, this study used three-dimensional drawing software to make twodimensional modeling of textured tools, take the model into finite element analysis software Advantedge and develop twodimensional cutting simulation by no micro texture and micro texture under the same conditions, using single variable control method. By comparison, the results show micro texture tools can reduce cutting force and the wear of cutting tool.
\end{abstract}

Keywords: - micro texture; cutting force; wear; Advantdge; finite element; $* * *$

\section{INTRODUCTION}

In the metal machining detailed analysis the contact area between the workpiece and the cutting tool and built-up edges formingprocess is entirely necessary to assess and instruct themetal machining. BUE produced precisely there plays a significant role during cutting process. This importance is raised due to the requirement that Surface finish required to meet the industry to develop a certain level of standards is the need of the relevant departments and the actual use. So the wear behavior of the cutting tool determines the accuracy of the workpiece to a large extent. In addition, The wear of the tool also affects the surface roughness of the machined workpiece, which is measured by the change in residual stress. In Xie, Q[1] it is considered that tool wear is vital on the residual stress state for a machined workpiece. The results of the analysis show that the residual stress on the surface of the workpiece increases as the wear of the flank face increases. The properties of the resulting workpiece surface is measured by four main parameters: the dimensional accuracy, the surface finish, the surface roughness and the residual stress state. In order to qualitatively analyze the wear state of the tool, the cutting force of the tool, one of the methods of indirect monitoring of tool wear, during the cutting process should be the object of study.

In the low velocity range of processing BUE can easily occur at contact-zone and built-up edge formation and builtup layers are visible, then low speed dry machining often avoids any forms of coolant and lubricant. Generally, in the roughing or semi-finishing stages of the workpiece, improving the machining efficiency, reducing tool wear and prolonging the tool life is major elements. However, Some other features of the workpiece require less quality, such as processing technology, machining accuracy, surface roughness, surface residual stress, etc. In the processing, BUE as a tool to participate in the processing can be generated and the size of the increase can protect the rake face of tool by selecting the appropriate cutting parameters. In Kümmel et al.[2] it was demonstrated that the degree of BUE coverage strongly affects the local wear rates at the cutting edge, thus demonstrating that built-up edges can be used as a protective layer against tool wear. So BUE should exist in long times to provide effective layer for cutting tool.

From the formation of BUE, the mechanism of the formation of BUE is the friction between the rake face and the chip. In Johannes kümmel et al.[2] the BUE structures are instable in the cutting process and lead to a deterioration of the workpiece surface. Using the method of transforming the coefficient of friction through making the texture on the rake face the forming conditions can be changed. The surface texture is mainly used in lubrication and improving efficiency conditions, such as Micro-pool Self-lubricating and MQL and so on. Gachot et al.[3] demonstrate that in dry friction the texture leads to tuneable frictional properties of contacting surface. In Etsion,[4] the author analyzes that the textures of the tribologically improve the wear behavior of the tool surfaces.

For the study of metal cutting tool, some research groups once made different attempts which are using micro-textures on the cutting tool rake face to obtain a better conclusion of cutting tool. In Kawasegi et al.[5] channel textures parallel and perpendicular to the cutting edge were used to improve the machinability of metalmachined with cemented carbide cutting tools. It further demonstrates thatthe direction of the used texture affects the machinability of metal material. The conclusion is that the difference in cutting force for textures is attributed to contact lengths betweenthe rake face and chip. 
This paper mainly studies that micro textured on a tool surface influences the wear behavior of the tool and cutting performance how to change the machinability of metal material by experimental and simulation analysis.

\section{EXPERIMENT SETUP}

\subsection{Workpiece and Tool Material}

In the cutting experiments, considered a variety of reasons, the workpiece material is aluminum alloy A5052 in a normal state. The choice of workpiece material and heat treatment of the reason why this choice is to facilitate the emergence of BUE. In addition, the requirement is BUE can stably exist on the textured tool and further be examined well. The chemical composition of the material, aluminum alloy A5052, is shown in Table-1.

Table 1: Chemical composition of workpiece material in

\begin{tabular}{|l|l|l|l|l|l|l|}
\hline $\mathrm{Si}$ & $\mathrm{Cu}$ & $\mathrm{Mg}$ & $\mathrm{Zn}$ & $\mathrm{Mn}$ & $\mathrm{Cr}$ & $\mathrm{Fe}$ \\
\hline 0.25 & 0.10 & 2.2 & 0.10 & 0.10 & $0.15 \sim 0.35$ & 0.40 \\
\hline
\end{tabular}

A dry metal turning was used with cylindrical workpiece with lengths of $50 \mathrm{~mm}$ or $100 \mathrm{~mm}$ and diameter of $58 \mathrm{~mm}$. The turning operation was using a machining centre Heller MC 16. The cutting tool used for the experiments was industrial cemented carbide with a composition of 94 vol.\% WC and 6 vol.\% Co.

\subsection{Design of Tool Texture}

Femtosecond laser was used to make microscale textures on the rake face of the tool because it has the advantage of high energy and high speed. In addition, the duration of the pulse is extremely short, which ensured that the rest of the rake face would not be melted or burned. For the micro-textures, which were manufactured in the rake face. The texture is evenly distributed on the rake face, occupying about $50 \%$ of the area of rake face The important parameters: the width of the texture was $50 \mu \mathrm{m}$; the depth of the texture was $1.5 \mu \mathrm{m}$; the direction of texture was perpendicular to the chip flow direction. The size parameters of texture including width and depth was the same for each simulation. In Fig-1 the textured tool with texture on the rake face was displayed. The initial temperature was $20^{\circ} \mathrm{C}$.

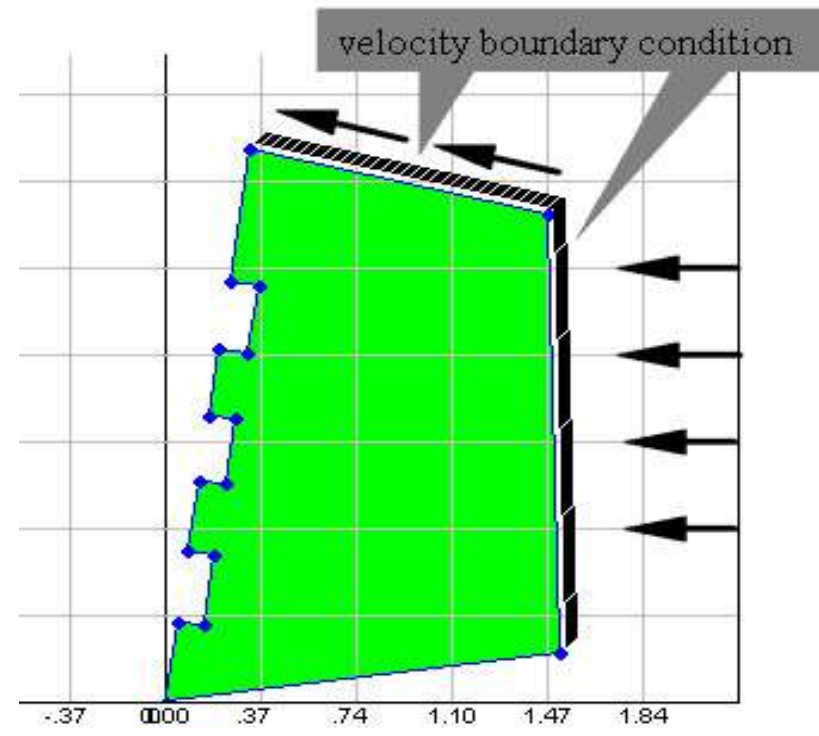

Fig 1: Textured cutting tool with texture on the rake face

\subsection{Cutting Conditions}

The cutting parameters were selected to facilitate subsequent examines and the results of the different cutting tools could be clearly distinguished. By comparison, the corresponding conclusions can be intuitively obtained. So the necessary cutting conditions were listed in Table-2 as shown below.

Table 2: Cutting conditions

\begin{tabular}{|l|l|l|}
\hline Cutting tool & Work material & Cutting $\operatorname{speed}(\mathrm{m} / \mathrm{min})$ \\
\hline Cemented carbide & Al-A5052 & $50-500$ \\
\hline
\end{tabular}

\begin{tabular}{|l|l|l|}
\hline Feed rate $(\mathrm{mm} / \mathrm{rev})$ & Depth of cut $(\mathrm{mm})$ & Lubrication \\
\hline 0.2 & 0.2 & Dry cutting \\
\hline
\end{tabular}

In Fig-2, A specific view of the turning process is displayed. The cutting velocity $500 \mathrm{~m} / \mathrm{min}$ was selected to avoid the impact of BUE due to only consider single factor, microtexture, for the wear examination. With the progress of cutting, when the cutting velocity reached the critical value, BUE will disappear.

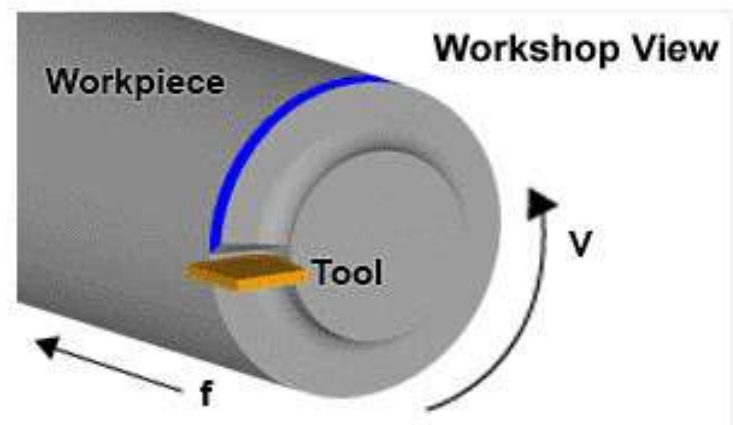

Feed direction

Fig 2: Model view of dry turning operation with cutting tool, workpiece, feed direction 


\section{RESULTS AND DISCUSSION}

\subsection{Effect of Untextured and Microtextured Tool}

\section{Forming BUE on Tool Wear by Simulation}

For tool wear, only by some experiments, is it not easy to obtain the accurate ideal results. In addition, due to change cutting parameters, making experiment required different texture of tools and workpieces would waste more material. In this paper the cutting simulation software Third Wave AdvantEdge was used to model machining. Numerical simulation experiment of cutting can provide intuitively related variables information of cutting process such as, cutting force, temperature, surface residual stress and other index which was difficult to measure with today's technology. To compare the wear of the tool with the textured and non-textured with keeping others parameters the same but only changing tool, the polynomial fit cutting force curve and real-time cutting force of the tool during machining is shown below.

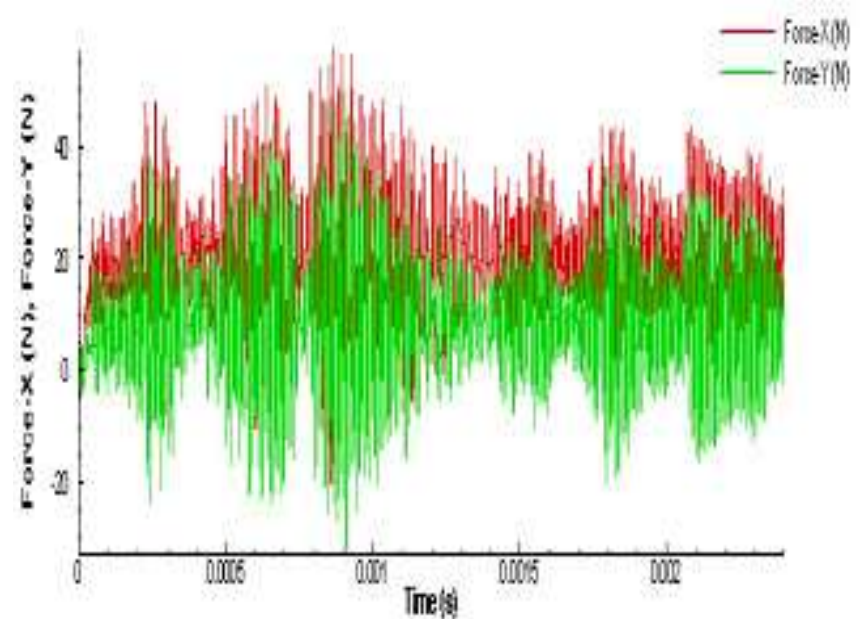

Fig 3: Time histories of the cutting force with non-textured tool for simulation

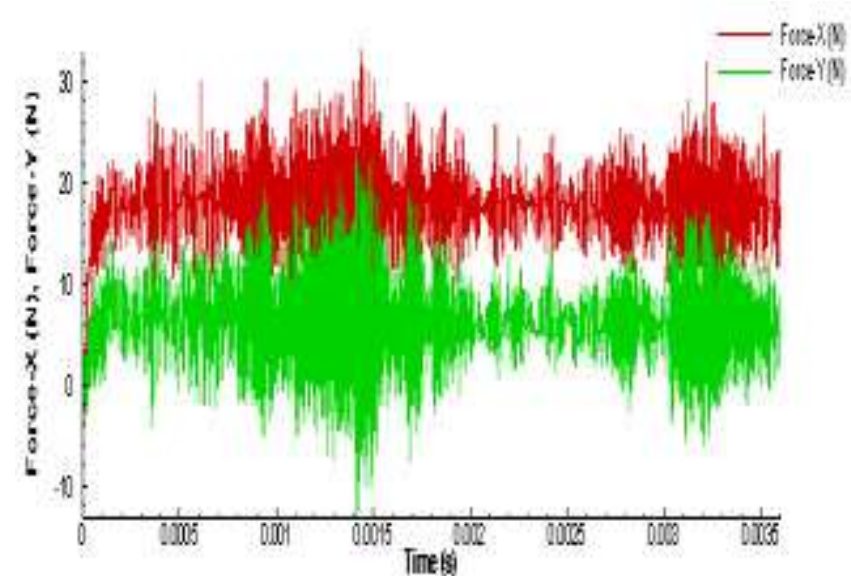

Fig 4: Time histories of the cutting forces with textured tool for simulation

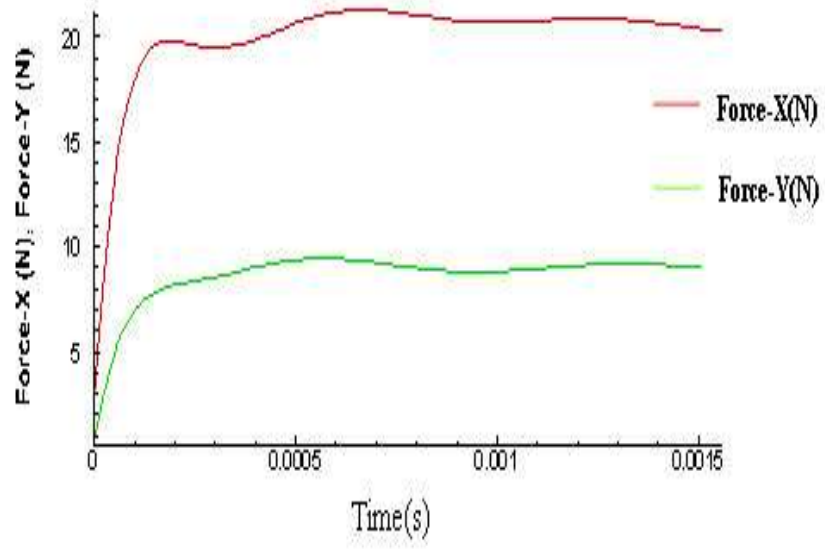

Fig 5: Polynomial fit cutting force curve with non-textured

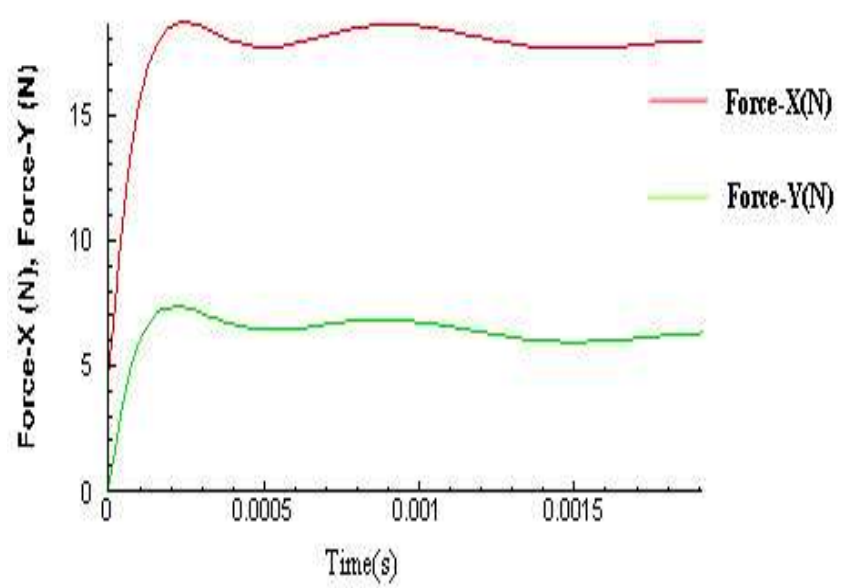

Fig 6: Polynomial fit cutting force curve with textured

By comparison of the cutting force with non-textured and textured tool in Fig-5,6 it can be seen that the cutting forces for textured tool were lower than those for non-textured tool. Compare Fig-3 and Fig-4, the amplitude of cutting force for non-textured tool and the average changing rate of force were higher than that textured tool.Compared to the non-texturing tool, the cutting force waveform of the textured tool is relatively stable. The increase of Force-X was greater than at Force-Y. So non-textured tool which was subjected to more alternating load would arise more wear than the textured tool. 


\subsection{Effect of Untextured and Textured on Tool's}

Wear

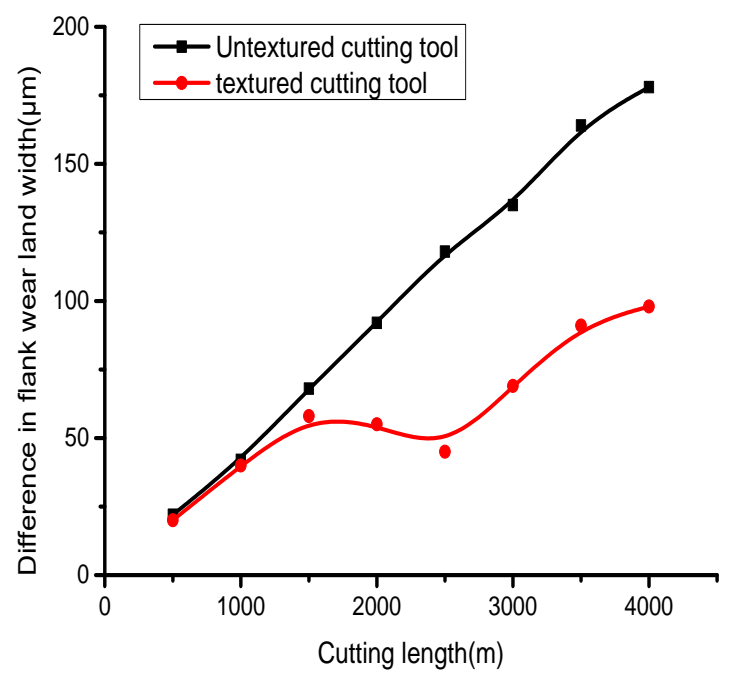

Fig 7: Changes of flank wear land width vs. the cutting length for the untextured and textured cutting tool

To clarify the wear behavior of the untextured and textured tool in the metal machining. The flank wear is measured in Fig.7. Here the reference data for the different tools is shown that was applied for the evaluation of the difference measures for wear analysis. For the final states of the cutting tools, the flank wear land width is higher for the untextured cutting tool. One reason for this change is that The presence of texture reduces the contact length and area between the tool-chip, which facilitates heat conduction and reduces the wear of the tool and the cutting environment temperature.

\section{CONCLUSION}

The results clearly indicate that different tools with textured and untextured on the rake face lead to different influences on the cutting performance and wear evolution over the cutting length after defined dry straight turning. The textured tool shows the smaller cutting force and lower wear, especially for the textured tool with higher cutting stability. The cutting tools were successfully fabricated with micro texture. The texturesenabled us to reduce the friction on the tool surfaces, decreasing the required cutting forces.

\section{REFERENCES}

[1] Xie,Q., Abdel E. Bayoumi, L. Alden Kendall. On tool wear and its effect on machined surface integrity.Journal of Materials Shaping Technology. 8,255-265

[2] Kümmel,J.,Jens Gibmeier, Erich Müller, Reinhard Schneider, Volker Schulze, Alexander Wanner,Detailed analysis of microstructure of intentionally formed built-up edges for improving wear behaviour in dry metal cutting
processofsteel,Wear,Volume 311, Issues 1-2,Pages 21-30.

[3] Gachot, C., Rosenkranz, A., Reinert, L. et al. Dry Friction Between Laser-Patterned Surfaces: Role of Alignment, Structural Wavelength and Surface Chemistry, Tribol Lett, 193-202

[4] Etsion, Izhak., State of the Art in Laser Surface Texturing, Journal of Tribology, Vol.127, 248-248

[5] Noritaka Kawasegi, Hiroshi Sugimori, Hideki Morimoto, Noboru Morita, Isao Hori, Development of cutting tools with microscale and nanoscale textures to improve frictional behavior, Precision Engineering, Volume 33, Issue 3 ,Pages 248-254, 